\title{
SOME MUSCULAR MANIFESTATIONS OF HYPOTHYROIDISM
}

BY

\author{
JOHN WILSON and JOHN N. WALTON
}

\author{
From the Neurological Unit, Department of Medicine, Royal Victoria Infirmary, Newcastle upon Tyne
}

\begin{abstract}
Although it has been recognized for many years that symptoms and signs indicating disordered function of the voluntary musculature may be prominent in patients with myxoedema, the muscular manifestations of hypothyroidism have received comparatively little attention in the British litera-
\end{abstract} ture. Recent reviews have, however, been given by Thomasen (1948), Piaggio Blancho and Malosetti (1950), Millikan and Haines (1953), Herbeuval, Cuny, and Larcan (1956), Dubanský, Svoboda, and Wiedermann (1957), and Perugini and Prati (1957).

Kocher (1892) reported that patients with sporadic cretinism or myxoedema often showed bulky musculature, diminished muscular power, and sluggish movement with or without "tetany". Hoffmann (1897) later described features suggestive of myotonia in a patient who had undergone thyroidectomy several times ; he pointed out that in this case there was a striking delay in muscular relaxation, reminiscent of that which occurs in myotonia congenita (Thomsen's disease). Since these early descriptions the syndrome of generalized muscular hypertrophy with sluggishness of muscular contraction and relaxation, which occurs in myxoedematous adults, has been referred to as "Hoffmann's syndrome". A similar disorder seen in cretinous infants is generally called the "DebréSemelaigne syndrome". Probably this disorder accounts for many cases of so-called acquired myotonia or myotonia acquisita (Talma, 1892). In fact, however, the abnormality of muscle function which results from hypothyroidism must be distinguished from true myotonia, as the overall slowness of muscular activity affects muscular contraction as well as relaxation and the typical electrical after-discharge of myotonia is not seen. Hence the term "pseudomyotonia" is a more appropriate description for the myxoedematous phenomenon.

Whereas it is not difficult in patients with florid myxoedema to appreciate that slowness of movement and stiffness of the voluntary muscles may be attributable to the thyroid disease, particularly when there is also marked muscular hypertrophy, we have been impressed by the fact that the muscular symptoms may not always follow the accepted form and may be the presenting feature in patients in whom hypothyroidism is otherwise clinically unobtrusive. We report below three cases in which diagnosis presented considerable difficulty but nevertheless the response to treatment was rapid and sustained.

\section{Case Reports}

Case 1.-M.E., an anxious, hypochrondriacal housewife, born in 1919, began in 1953 to complain of intolerance of heat, profuse sweating, and loss of weight. A smooth enlargement of the thyroid gland had been present for 10 years. She was found to have warm. moist palms, tachycardia of $108 / \mathrm{min}$., and blood pressure of $165 / 85 \mathrm{~mm}$. Hg. The B.M.R. was $+23 \%$. For the next two years the patient was treated in turn with neomercazole, Lugol's iodine, and methyl thiouracil in an unsatisfactory attempt to achieve control of the thyrotoxic symptoms. A subtotal thyroidectomy was eventually performed by Professor A. G. R. Lowdon at the end of September, 1955. Immediately after the operation there was a mild thyrotoxic crisis, but she made sufficiently rapid progress post-operatively for her to be discharged home six days after operation. In November, 1955 , the patient complained that her fingers and facial muscles had been stiff since her return home, and her face slightly swollen. At that time she was thought to be euthyroid. In early 1956 she was referred to a psychiatrist because of a complaint of bizarre aches and pains affecting all limbs. No psychological cause for the patient's symptoms was evident but no satisfactory alternative explanation was offered. She was seen again by a physician who mentioned that although she had gained 3 stones in weight post-operatively, there were no clinical signs of hypothyroidism. As the muscular pain and aching persisted the patient was referred to one of us (J.N.W.). It was then observed that there was generalized muscular hypertrophy which was especially marked in the quadriceps and calves. All the voluntary muscles were stiff and felt indurated ; movements were slowly performed and on percussion of the deltoids and quadriceps there was " dimpling " of the muscle, lasting for over two seconds, and similar to that seen in myotonia. Although the pulse rate was $90 / \mathrm{min}$., the skin felt cold, the patient was lethargic, constipated, and looked mildly myxoedematous. She refused readmission 
to hospital for investigation ; in view of a presumptive clinical diagnosis of Hoffman's syndrome, she was treated with tri-iodothyronine, $40 \mu \mathrm{g}$ daily. When next seen one week later she was asymptomatic and composed. All the muscular pain and stiffness had disappeared. Within a few weeks the muscular hypertrophy was much less evident. In June, 1958, dried thyroid extract, grains 2 daily, was satisfactorily substituted for tri-iodothyronine; the patient has remained well since.

The clinical picture in this case was characteristic of Hoffmann's syndrome and the therapeutic response to tri-iodothyronine, and later to thyroid extract, was prompt and sustained.

Case 2.-R.N., a health visitor, was born in 1917. In 1944 she underwent a partial thyroidectomy for toxic goitre. Almost immediately following this operation she began to complain of aches and pains in all her limbs after exertion, like an "after-tennis feeling". These symptoms persisted in a degree insufficient to interfere with her work. In April, 1957, having swallowed a fish-bone, she had an oesophagoscopy under a general anaesthetic and the bone was removed. During anaesthesia intravenous succinylcholine was used ; the patient recovered normally from the anaesthetic but next day all her limbs became completely paralysed and flaccid. This severe weakness persisted for 24 hours and then slowly remitted over the following week. In May, 1957, after several attacks of renal colic she had a nephrectomy for hydronephrosis due to an aberrant artery. Succinylcholine was again used, and on this occasion, flaccid paralysis of the limbs was present immediately after the operation and again persisted for 24 hours. During both periods of paralysis there was slight dysphagia and dysarthria but no respiratory embarrassment. Serum potassium determinations during each attack of paralysis were normal and there was no response to prostigmine. In December, 1957, the patient was referred to one of us (J.N.W.) as a possible case of polymyositis, as by now the generalized muscular aching and pains in the limbs were more severe. For the first hour after rising in the morning she would feel well and symptom-free, but then progressively throughout the day she would become slower and easily fatigued ; she had particular difficulty in climbing stairs. When tired, the "after-tennis feeling" in the muscles was particularly troublesome. Because of an increase in these symptoms, she was by this time unable to follow her occupation as a health visitor.

On examination there were no clinical abnormalities ; in particular there was no muscular wasting, weakness, tenderness, or hypertrophy, and no clinical myotonia could be demonstrated, either on relaxation of the grip or on percussion of muscles. The tendon reflexes were symmetrically brisk and the plantar responses were both flexor. The patient appeared to be euthyroid.

Investigations.-The following investigations were carried out :-

Blood.-Haemoglobin 13.9 g./100 ml., W.B.C. $6,500 /$ c. mm. (differential count normal), E.S.R. $5 \mathrm{~mm}$. in one hour (Westergren), plasma sodium $138 \mathrm{mEq}$./ litre, plasma potassium $4.6 \mathrm{mEq}$./litre, serum calcium $9.6 \mathrm{mg} . / 100 \mathrm{ml}$., plasma phosphate $2.4 \mathrm{mg} . / 100 \mathrm{ml}$., total serum proteins $7.2 \mathrm{~g} . / 100 \mathrm{ml}$. (albumin $4.9 \mathrm{~g} . / 100$ ml., globulin $2.3 \mathrm{~g}$. $/ 100 \mathrm{ml}$.), serum cholesterol 255 mg./100 ml., fasting blood sugar $76 \mathrm{mg} . / \mathrm{ml}$.

Using the tanned red cell technique (Owen and Smart, 1958), Dr. S. G. Owen demonstrated circulating antibodies to thyroglobulin in the venous blood to a dilution of 1 in 675.

Urine.-No albumin or reducing substances were detected and no abnormal deposit was found on microscopy.

The creatinine level was $1.57 \mathrm{~g}$. in 24 hours and the creatine $0.03 \mathrm{~g}$. in 24 hours.

The basal metabolic rate was $+2 \%$ and an $1^{131}$ uptake test was well within normal limits. An electrocardiogram was normal and a muscle biopsy taken from the left deltoid yielded a specimen in which no significant histological change could be detected. After the administration of insulin and glucose the serum potassium fell to $3 \mathrm{mEq}$./litre but no muscular weakness could be demonstrated.

Electromyography.-Electromyograms were recorded, using concentric needle electrodes, from the left deltoid, the left biceps brachii, and the right quadriceps. No spontaneous activity was recorded ; in particular, there was no fibrillation and no myotonic discharges were obtained on moving the electrode. Volitional activity was also normal ; no excess of polyphasic or shortduration potentials was recorded.

Treatment.-The patient was treated initially with lactose control tablets but her symptoms remained unchanged. The administration of tri-iodothyronine in a daily dosage of $40 \mu \mathrm{g}$. was followed by prompt remission of symptoms and a feeling of well-being. During succeeding weeks, all muscular pain and weakness vanished, the patient became energetic and symptomfree, and was able to return to her previous occupation. After six months' treatment with tri-iodothyronine, dried thyroid extract, 3 grains daily, was begun, and two weeks later, tri-iodothyronine was withdrawn. In another two weeks the muscular pain and aching had returned. Owing to increasingly severe symptoms, tri-iodothyronine was again given, with prompt and sustained remission and the patient has remained well for one year, taking $40 \mu \mathrm{g}$. of this drug daily.

In this case there was no clinical evidence of hypothyroidism, apart from the muscular symptoms, and all investigations of thyroid function were normal, save for the discovery of antibodies to thyroglobulin, a finding suggesting a previous thyroiditis (Hashimoto disease). The relapse on treatment with thyroid extract suggests either that the particular batch of tablets was inactive or that there was a defect in the breakdown of thyroxin to tri-iodothyronine. The episodes of paralysis following succinylcholine suggest an unusual sensitivity of the muscle fibre membrane to this drug ; but the relationship to hypothyroidism and the reason 
for delay in the development of the first episode of weakness are not apparent.

Case 3.-E. T., a housewife, was born in 1917. In 1950, after two years of breathlessness, palpitations, sweating, tremor, and loss of weight, she underwent a partial thyroidectomy; a small nodular goitre was discovered. Her symptoms persisted and in 1954 a further partial thyroidectomy was performed. Once more her symptoms were unchanged and yet another operation to remove remaining thyroid tissue was carried out in 1955.

Three months after this operation the patient began to experience several attacks each day in which she experienced painful cramps affecting mainly the left forearm and hand, each lasting one or two minutes. These attacks could be provoked by exercise and were often accompanied by superficial tingling. The right hand was similarly though mildly affected. About one month later similar cramps developed in both legs. Since the cramps resembled the carpopedal spasms of tetany, repeated serum calcium and phosphateestimations were performed, but all were normal. The patient was then referred to one of us (J. N. W.). She mentioned that her appetite was poor, she was losing weight, and was very constipated. Since her last operation she had felt cold, her skin was dry, and her hair falling out. Her muscles had also felt stiff and painful and all movement was slower than it had been previously.

On examination the patient was thin and nervous ; despite her complaints of feeling cold her palms were warm and moist, but the pulse rate was $72 / \mathrm{min}$., the blood pressure $115 / 80 \mathrm{~mm}$. Hg. There was no residual palpable thyroid swelling. Some brown pigmentation was present around the neck, on the forearms and iliac crests. In the limbs, although all the muscles were thin, there was no localized muscular atrophy, tenderness, or weakness. There was, however, marked delay in relaxation of the grip, resembling myotonia, and persistent dimpling of the muscle was present after percussion. The consistency of the muscles appeared to be increased and there was an increased resistance to passive stretching throughout, but no hypertrophy was evident. All the tendon reflexes were brisk, without any evidence of delay in muscular contraction or relaxation; the abdominal reflexes were present and the plantar responses flexor. On application of a tourniquet to the left upper limb, a spasm of the left hand, very reminiscent of tetany, was produced. Chvostek's sign was negative. It was felt that although many of the patient's symptoms were those of a chronic anxiety state, there was definite evidence of hypothyroidism which was probably the explanation of the symptoms referrable to the voluntary muscles.

Investigations.-The following investigations were carried out :-

Blood.-Haemoglobin $11.6 \mathrm{~g} / 100 \mathrm{ml}$., white cell count $9,800 /$ c. mm. (differential count normal), E.S.R. $1 \mathrm{~mm}$. in one hour (Westergren), plasma sodium 138 mEq./litre, plasma potassium $4.1 \mathrm{mEq}$./litre, serum calcium $9.2 \mathrm{mg} . / 100 \mathrm{ml}$. plasma phosphate $2.5 \mathrm{mg} . P$. $/ 100 \mathrm{ml}$., total serum proteins $5.8 \mathrm{~g} . / 100 \mathrm{ml}$.
Urine.-No albumin or reducing substance was detected.

In two specimens urinary 17 -ketosteroids were $1.2 \mathrm{mg}$. and $1.5 \mathrm{mg} . / 24$ hours respectively. The B.M.R. was $-4 \%$.

The uptake of $1^{131}$ was in the hypothyroid range ; $4.8 \%$ of initial dose at 1.5 hours ; $5.3 \%$ at 4 hours ; $12.4 \%$ at 26 hours, and $10.8 \%$ at 49.5 hours.

Thorn's test over 48 hours showed normal depression of the blood eosinophil count.

Electromyography.-Electromyograms recorded from the left deltoid, the left forearm, and the left quadriceps with concentric needle electrodes were entirely normal. No myotonic discharges were recorded.

Treatment.-Procaine amide, in a dosage of $750 \mathrm{mg}$. four times daily, was given initially with a considerable reduction in muscular stiffness and improved relaxation, but the painful cramps persisted. Thereafter triiodothyronine, $20 \mu \mathrm{g}$. twice daily, was given. Within a few days, all muscular pain and stiffness had disappeared and the carpopedal spasms were greatly reduced in frequency and severity. After a few weeks of treatment these symptoms were no longer prominent and the patient returned to normal activity. Anxiety symptoms such as palpitations, malaise, and excessive sweating persisted intermittently and presented considerable difficulties in subsequent management. On two occasions over the next three years tri-iodothyronine therapy was discontinued but on each occasion muscular pain and stiffness and painful cramps recurred. The clinical picture is now dominated by anxious hypochondriasis, but muscular symptoms are no longer prominent. Further investigation has revealed no evidence of hypopituitarism or of Addison's disease.

In this case, the coexistence of a severe chronic anxiety state led to considerable difficulties in both diagnosis and management. Muscular pseudohypertrophy was not present and the carpopedal spasms favoured a diagnosis of hypoparathyroidism, although no abnormality of calcium and phosphorus metabolism could be demonstrated. The muscular pain and stiffness was, however, suggestive of hypothyroid myopathy and the $1^{131}$ uptake test was diagnostic of hypothyroidism. The muscular symptoms resolved after treatment with triiodothyronine.

\section{Discussion}

These three cases have in common the following features :-

(a) In each, symptoms followed thyroidectomy.

(b) The symptoms and signs of muscular dysfunction and those of hypothyroidism remitted, usually completely, on treatment with tri-iodothyronine. For this reason and because the clinical features in each case resemble some of those previously described in hypothyroidism, it appears that the muscular symptoms could be attributed to a deficiency of thyroid hormone. The muscular 
disorders which have been described in association with hypothyroidism are, according to Thomasen (1948) and Perugini and Prati (1957) :-

(1) A myotonoid syndrome (pseudomyotonia, myotonia acquisita).

(2) Muscular hypertrophy in adults, with firm, often painful muscles ; power and tone are variable, and both contraction and relaxation are usually sluggish.

(3) Muscle hypertrophy with reduced or increased power in infants suffering from sporadic cretinism, giving the appearance of "the infant Hercules", the Debré-Semelaigne syndrome (Debré and Semelaigne, 1935).

(4) Muscle cramps, which sometimes resemble classical tetany.

(5) Rare atrophic forms (Canali, 1941 ; Nick, 1943 ; Rimbaud and Passouant, 1947 ; Piaggio Blancho and Malosetti, 1950).

These phenomena may occur singly or in any combination, and may be of varying severity. They have been described in patients after total (Hoffmann, 1897) and partial thyroidectomy (Crispell and Parson, 1955; Hofman-Credner, 1956), after $1^{131}$ in ablation doses (Gilbert-Dreyfus, Zara, and Gali, 1954), after radiotherapy (Lenègre and Huguenin, 1941), after "lipiodol" (Sigmir, quoted by Herbeuval et al., 1956), in so-called "spontaneous" myxoedema (Thomasen, 1948), in hypothyroidism secondary to hypopituitarism (Dubanský et al., 1957), and in sporadic cretinism (Debré and Semelaigne, 1935).

The mechanism of these muscular symptoms is unknown, and we have no satisfactory explanation for their patho-physiology ; in particular it cannot be explained why only a proportion of patients with myxoedema are so affected. To describe the changes as "myxoedema of the muscles" does not contribute anything to our understanding of the condition, and definitive metabolic studies of muscular function in such cases are lacking.

Pseudomyotonia at first sight resembles true myotonia in that there is delayed relaxation of the grip, worse in cold weather ; the phenomenon is, however, quite different. It is apparent that in these cases muscular contraction as well as relaxation is slowed, and the characteristic after-discharge of myotonia is absent electromyographically, as are the typical bizarre insertion discharges associated with the latter phenomenon. Direct percussion of affected muscle does, however, produce a local dimpling as in true myotonia. The response to quinine in pseudomyotonia is said to be poor, though Crispell and Parson (1955) claim a good response in one patient ; it is of interest that in our Case 3, there appeared to be a definite improvement with procaine amide, a remedy which relieves myotonia (Geschwind and Simpson, 1955 ; Leyburn and Walton, 1959).

Muscular hypertrophy may be generalized or localized, predominantly affecting the calves and thighs, although the facial muscles can also be markedly involved. Muscle power is usually decreased, despite the hypertrophy, and the movements are usually sluggish, sharing in the general torpor of the myxoedematous patient. Increase of power has, however, been described, especially in the Debré-Semelaigne syndrome. The so-called Woltman tendon reflex in such cases, which depends upon the demonstration of an unusual slowness of muscular contraction and relaxation when the knee jerk is being elicited, may be of considerable diagnostic value (Chaney, 1924 ; Lambert, Underdahl, Beckett, and Mederos, 1951).

Muscular pain and cramps are usually seen in those patients with enlarged, brawny muscles but can occur in others, even when there is no other clinical evidence of hypothyroidism. Muscular pain on exertion, as in cases of so-called myotonia paradoxa, and resembling also in some respects the symptoms of McArdle's myopathy due to a defect in muscle glycogen breakdown (McArdle, 1951), may be the outstanding clinical feature, as in our Case 2. Symptoms suggesting classical tetany may also be seen, as in Case 3 .

The atrophic form may resemble the more familiar muscular dystrophies (Piaggio Blancho and Malasetti, 1950) but several of the reported cases are not well attested and there may have been alternative explanations for the muscular atrophy (Rimbaud and Passouant, 1947 ; Dubanský et al., 1957).

These variable clinical phenomena may give rise to considerable difficulty in diagnosis, especially if the usual clinical features of myxoedema are unobtrusive ; it is only too easy for symptoms of this nature, for which no ready explanation is forthcoming, to be dismissed as being psychogenically determined. In our Cases 1 and 3 the symptoms were at different times attributed by several observers to hysteria or anxiety while in Case 2 a diagnosis of endogenous depression was at one time entertained. It is important to emphasize that there is no parallel between the degree of hypothyroidism and the severity of the muscular symptoms and signs, nor do the latter present a consistent clinical picture. Diagnosis may depend on a "high index of suspicion". A low basal metabolic rate, high serum cholesterol level, reduced $1^{131}$ uptake, and low protein-bound iodine may afford confirmation of the diagnosis but the results of these tests may be only slightly abnormal (myxoedema frustes of 
French writers) ; indeed they may even be normal as in our Case 2, in which the diagnosis finally depended upon the finding of a raised titre of antibodies to thyroglobulin in the patient's serum, as well as upon the therapeutic test.

Unlike the usual findings in myotonia congenita and paramyotonia, in which the electrical phenomena may represent a recurring excitation of muscle fibres, the electromyogram in myxoedematous pseudomyotonia is usually normal. Pseudomyotonia therefore, is probably due to a delay in relaxation of individual muscle fibres after a single excitation, and may represent an abnormally slow release of energy from the energy-rich bonds within the muscle cell, as a part of a general reduction in metabolic rate. Electrical stimulation of myxoedematous muscles may provoke a myotonoid reaction but strength-duration curves from these muscles are usually normal or show only a slightly increased chronaxie (Bourguignon, 1939 ; Picard, Horeau, Kerneis, Lhermitte, and Lescaudron, 1955 ; Svoboda, Dubanský, and Myslivý, 1956). Muscle specimens removed by biopsy, even from hypertrophied muscle, are usually normal, as in our Case 2. Picard et al. (1955) found "hypertrophy" of sarcoplasm, accentuation of both longitudinal and transverse striation, coexistence of both hypertrophic and atrophic fibres, and increased numbers of sarcolemmal nuclei in material from their cases, but these descriptions are not entirely convincing. Inflammatory changes, fatty infiltration, and fibrosis have not been described. Thomasen (1948) believed that the muscle hypertrophy was not due to genuine hyperplasia or hypertrophy of the fibres, but to oedema. Hesser (1940) has put forward the interesting, but as yet unconfirmed, view that the hoarseness which is so striking a feature of myxoedema is due in part to hypertrophy of the laryngeal muscles and that the deafness which occasionally occurs depends upon enlargement of the intrinsic musculature of the ear.

In the last resort, diagnosis depends on the complete remission of symptoms with thyroid extract or more dramatically with tri-iodothyronine. It is difficult to explain why symptoms in Case 2 should have responded to tri-iodothyronine and not to thyroid extract. Either the batch of thyroid extract utilized was inactive (which seems unlikely) or else in this case there was some derangement of the metabolic mechanism whereby absorbed thyroxin is converted into tri-iodothyronine within the body.

The exact incidence of muscular complications of hypothyroidism has never been estimated, and although the three patients in the present report were female, there does not appear to be a genuine sex difference. We suspect that these muscular manifestations are more frequent than is generally realized, minor degrees being overlooked in florid myxoedema, or wrongly ascribed to other causes such as intermittent claudication (Ericsson and Lindquist, 1945). Myxoedematous myopathy should certainly be considered as a possibility in all patients who complain of generalized muscular pain, aching or stiffness, particularly if this develops after exertion.

\section{Summary}

Three cases are described in which symptoms indicating disordered function of the voluntary musculature were prominent; these symptoms, which included muscular pain and stiffness, accentuated by exertion, and in one case painful cramps resembling tetany, were shown to be due to hypothyroidism, and responded to treatment with tri-iodothyronine. In each case, the other symptoms of hypothyroidism were relatively unobtrusive.

The clinical features of myxoedematous pseudomyotonia, and its differentiation from true myotonia, are discussed. The view is expressed that this condition is more common than is generally realized, and should be borne in mind as a possible diagnosis in all patients complaining of generalized muscular pain and stiffness.

We wish to thank Professor A. G. R. Lowdon, Dr. A. Zinovieff, and Mr. J. K. McCollum for referring the patients who are the subject of this report ; we are also indebted to Dr. K. Schapira and Mr. A. Hope for
help in the translation of German and Italian papers.

\section{REFERENCES}

Bourguignon, G. (1939). Rev. neurol., 71, 548.

Canali, G. (1941). Riv. clin. med., 42, 301

Chaney, W. C. (1924). J. Amer. med. Ass., 82, 2013.

Crispell, K. R and Parson, W. (1955). Trans. Amer. Goiter Ass., 1954, 399 .

Debré, R., and Semelaigne, G. (1935). Amer. J. Dis. Child., 50, 1351 Debré, R., and Semelaigne, G. (1935). Amer. J. (1957). Nervenarzt, Dubanský, B.

Ericsson, E., and Lindquist, T. (1945). Acta med. scand., 121, 132.

Geschwind, N., and Simpson, J. A. (1955). Brain, 78, 81.

Geschwind, N., and Simpson, J. A. (195., (1954). Presse méd., 62, 1553 .

Herbeuval, R., Cuny, G., and Larcan, A. (1956). Rev. méd. Nancy, 81, 1010.

Hesser, F. H. (1940). Bull. Johns Hopk. Hosp., 66, 353.

Hoffmann, J. (1897). Dtsch. Z. Nervenheilk., 9, 278.

Hofmann-Credner, D. (1956). Wien. Z. inn. Med., 37, 197.

Kocher, T. (1892). Disch. Z. Chir., 34, 566.

. Underdahl, L. O.. Beckett, S., and Mederos, L. O. (195i). J. clin. Endocr., 11, 1186.

(1951). J. clin. Endocr., (1941). Bull. Soc. Méd. Hôp. Paris, 3rd series, p. 650 .

3rd series, p. 650.
Leyburn, P., and Walton, J. N. (1959). Brain, 82, 81.

McArdle, B. (1951). Clin. sci., 10, 13.

Millikan, C. H., and Haines, S. F. (1953). Arch. intern. med., 92, 5.

Milikan, (1943). Les atrophies myopathiques liées à l'insuffisance thyroidienne acquise de l'adulte. Thèse de Paris. Quoted by Perugin and Prati (1957).

Owen S. G., and Smart, G. A. (1958). Lancet, 2, 1034

Owen, S. G., and Smart, G. A. (1958). Lancet, 2, 1034. 24.

Perugini, S., and Prati, P. L. (1957). Med. int. (1950). Arch. urug. Med., 37, 341 .

Picard, R Horeau, J., Kerneis, J., Lhermitte, R., and Lescaudron, A. (1955). Sem. Hôp. Paris, 31, 1553.

Rimbaud, L., and Passouant, P. (1947). Rev. neurol., 79, 81.

Rvoboda, E., Dubanský, B., and Myslivý, M. (1956). Cas. Lék. Ces., 95,912 .

Talma, S. (1892). Dtsch. Z. Nervenheilk., 2, 197.

Thomasen, E. (1948). Myotonia. Copenhagen. 